\title{
Similar serum lipoprotein reductions by lipid-lowering diets with different polyunsaturated: saturated fat values
}

\author{
BY INGA-BRITT GUSTAFSSON, J. BOBERG, B. KARLSTRÖM, \\ H. LITHELL AND B. VESSBY* \\ Department of Geriatrics, University of Uppsala, Uppsala, Sweden
}

(Received 17 March 1982 - Accepted 8 July 1983)

\begin{abstract}
1. Lipid-lowering diets enriched in polyunsaturated fat decrease the serum cholesterol in hyperlipoproteinaemia, usually by reducing both the low-density-lipoprotein (LDL) and high-density-lipoprotein (HDL) cholesterol concentrations. The aim of the present study was to investigate whether the effects on LDL could be maintained but those on HDL cholesterol be diminished by reducing the ratio, polyunsaturated: saturated fat $(\mathrm{P}: \mathrm{S})$ of the diet.

2. Twenty hyperlipoproteinaemic patients (six with type IIa, eight with type IIb and six with type IV) in a metabolic ward were given two fat-modified diets during two consecutive 3-week periods in a randomized order. The diets were identical with regard to nutrient composition but differed with regard to the $P: S$ values, which were 2.0 and 1.3 respectively.

3. The lipoprotein-lipid composition and serum apolipoprotein concentrations were similar at the end of the two dietary periods in type II a and type IV patients but in type II b patients a more pronounced reduction of the LDL-cholesterol concentration by $9 \%(P<0.05)$ was achieved on the diet with the higher $\mathrm{P}: \mathrm{S}$ value. The HDL-cholesterol did not differ significantly.

4. The results indicate that increasing the $P: S$ value of lipid-lowering diets from 1.3 to 2.0 does not offer a great advantage with regard to the lipoprotein-lipid reductions achieved in moderate hyperlipoproteinaemia.
\end{abstract}

Increased serum lipid levels can be reduced by treatment with lipid-lowering diets. Recent studies (Shepherd et al. 1978; Ernst et al. 1980; Shepherd et al. 1980; Vessby et al. 1980a, b; Lewis et al. 1981; Schaefer et al. 1981) have indicated that the serum cholesterol reduction achieved corresponds not only to a reduction of the concentration of cholesterol in the low-density-lipoproteins (LDL), but also of ten to a reduction of the level of cholesterol in the high-density-lipoproteins (HDL). The reduction of LDL-cholesterol is presumably beneficial. The decrease of the HDL-cholesterol concentration is probably less desirable as judged from epidemiological findings indicating that a high HDL-cholesterol concentration is associated with a low incidence of coronary heart disease (Gordon et al. 1977).

In a study by Shepherd et al. (1978), healthy men were given a lipid-lowering diet with a very high value for the ratio between the contents of polyunsaturated and saturated fatty acids $(\mathbf{P}: \mathbf{S})$. This was associated with a reduction of the HDL-cholesterol which was more pronounced than in other studies (Ernst et al. 1980; Vessby et al. 1980 a, b; Lewis et al. 1981; Schaefer et al. 1981) involving diets with more moderately elevated P:S values. This suggested that the reduction achieved might be proportional to the $\mathrm{P}: \mathrm{S}$ value of the diet.

We have demonstrated in earlier studies (Vessby et al. 1980a) that the reductions of HDL-cholesterol and LDL-cholesterol during treatment with lipid-lowering diets show different time-courses. This indicates that the decreases of HDL-cholesterol and LDLcholesterol are due to different mechanisms and thus may show different responses to diets with high and low $P: S$ values respectively.

In the present study the patients, in a metabolic ward, were treated with two diets with high and moderate contents of polyunsaturated fat in a randomized order. The aim of the study was to investigate whether the effects on LDL-cholesterol could be maintained but 
Table 1. Composition (energy \%) of lipid-lowering diets

\begin{tabular}{|c|c|c|c|c|c|c|c|}
\hline \multirow{2}{*}{$\begin{array}{c}\text { Dietary } \\
\text { polyunsaturated: } \\
\text { saturated fat } \\
\text { value }\end{array}$} & \multirow[b]{2}{*}{ Protein } & \multirow[b]{2}{*}{ Carbohydrates } & \multicolumn{5}{|c|}{ Fat (mg/10 MJ) } \\
\hline & & & Total & $\mathbf{S}$ & $\mathbf{M}$ & $\mathbf{P}$ & Chol \\
\hline 2.0 & 20 & $45^{*}$ & 35 & $8 \cdot 0$ & $10 \cdot 0$ & $16 \cdot 0$ & 228 \\
\hline $1 \cdot 3$ & 20 & $45^{*}$ & 35 & $11 \cdot 0$ & $10 \cdot 0$ & $14 \cdot 0$ & 230 \\
\hline
\end{tabular}

S, Saturated; M, monounsaturated; P, polyunsaturated; Chol, cholesterol.

* Refined sugar restricted.

Table 2 The relative fatty acid composition of the lipid-lowering diets with polyunsaturated: saturated fat $(P: S)$ values of $1 \cdot 3$ and $2 \cdot 0$

(Mean values with standard errors were calculated from the average value of each day of the week. For each daily menu, five to eight determinations were done)

\begin{tabular}{|c|c|c|c|c|c|c|}
\hline \multirow[b]{3}{*}{ Fatty acids } & \multicolumn{6}{|c|}{ P:S value of diet } \\
\hline & \multicolumn{3}{|c|}{$1 \cdot 3$} & \multicolumn{3}{|c|}{$2 \cdot 0$} \\
\hline & Mean & SEM & Range & Mean & SEM & Range \\
\hline $12: 0$ & $6 \cdot 2$ & 0.3 & $5 \cdot 7-7 \cdot 2$ & 1.0 & $0 \cdot 1$ & $0.9-1 \cdot 4$ \\
\hline $14: 0$ & $3 . \overline{8}$ & $0 \cdot 3$ & $3 \cdot 3-4 \cdot 3$ & 1.9 & $0 \cdot 2$ & $1 \cdot 5-2 \cdot 6$ \\
\hline $16: 0$ & $15 \cdot 6$ & 0.2 & $15 \cdot 1-16 \cdot 5$ & $14 \cdot 2$ & 0.2 & $13 \cdot 4-15 \cdot 3$ \\
\hline $18: 0$ & 6.0 & 0.2 & $5 \cdot 6-6 \cdot 2$ & 7.0 & 0.1 & $6 \cdot 6-7 \cdot 3$ \\
\hline Total saturated & $31 \cdot 6$ & 0.5 & $30 \cdot 4-33 \cdot 5$ & $24 \cdot 2$ & $0 \cdot 4$ & $22 \cdot 7-25 \cdot 9$ \\
\hline $16: 1 \omega 7$ & $1 \cdot 0$ & 0.1 & $0.8-1 \cdot 3$ & $1 \cdot 1$ & 0.1 & $1 \cdot 0-1 \cdot 3$ \\
\hline $18: 1 \omega 9$ & $26 \cdot 3$ & 0.2 & $25 \cdot 5-26 \cdot 9$ & $27 \cdot 4$ & 0.2 & $26 \cdot 7-27 \cdot 8$ \\
\hline Total monounsaturated & $27 \cdot 3$ & $0 \cdot 2$ & $26 \cdot 7-28 \cdot 0$ & 28.5 & 0.2 & $27 \cdot 7-29 \cdot 2$ \\
\hline $18: 2 \omega 6$ & $37 \cdot 4$ & 0.5 & $35 \cdot 4-39 \cdot 1$ & $44 \cdot 3$ & 0.5 & $42 \cdot 7-46 \cdot 5$ \\
\hline $18: 3 \omega 3$ & 3.7 & 0.2 & $3 \cdot 1-4 \cdot 3$ & $2 \cdot 8$ & 0.2 & $2 \cdot 2-3 \cdot 3$ \\
\hline Total polyunsaturated & $4 l \cdot 1$ & 0.6 & $38 \cdot 5-43 \cdot 0$ & $47 \cdot 3$ & 0.5 & $45 \cdot 9 \cdot 49 \cdot 4$ \\
\hline P:S & $1 \cdot 3$ & $0 \cdot 0$ & $1 \cdot 2-1 \cdot 4$ & $2 \cdot 0$ & $0 \cdot 0$ & $1 \cdot 8-2 \cdot 2$ \\
\hline
\end{tabular}

those on HDL-cholesterol be diminished by reducing the P:S value from $2 \cdot 0$ to $1 \cdot 3$. An optimal lipid-lowering diet would presumably cause a reduction of LDL-cholesterol without a concomitant decrease (or even better an increase) of the HDL-cholesterol concentration.

\section{MATERIALS AND METHODS}

Design of the study

During two consecutive 3-week periods in a metabolic ward the patients were treated with two lipid-lowering diets with P:S values of 1.3 or 2.0 in a random order. The serum lipoprotein patterns were studied at the end of the two dietary periods. Three or four times weekly the fasting serum triglyceride and cholesterol concentrations, the body-weights and the fatty acid compositions of the serum lipid esters were determined.

\section{Diets}

The lipid-lowering diets used in this study were based on ordinary Swedish food and planned as a 1-week menu. Their compositions are presented in Table 1 and have been described 
in detail elsewhere (Boberg et al. 1981). The compositions of the two diets were identical with regard to the proportion of fat, carbohydrates and protein and cholesterol content, but different with regard to the fat quality. The difference in fat quality was achieved by using different margarines. Otherwise the two diets were the same. The P:S values of the two diets were 1.3 and 2.0 . The relative fatty acid compositions of the two diets are given in Table 2. The calculated fibre contents of the two diets (mean and SD) were identical (25.3 (3.4) $\mathrm{g} / 10 \mathrm{MJ})$ as were the contents of vitamin C (191 (58) $\mathrm{mg} / 10 \mathrm{MJ})$. The energy intake was calculated individually to assure a steady body-weight.

\section{Patients}

Twenty patients took part in the study: six patients with hyperlipoproteinaemia (HLP) type II a, eight patients with HLP type II b and six patients with HLP type IV according to the World Health Organization criteria (Beaumont et al. 1970). The type II a group consisted of three men (age range 30-60 years) and three women (age range 50-59 years), the type II b group of four men (age range 51-59 years) and four women (age range 41-65 years) and the type IV group of four men (age range 51-59 years) and two women (58 and 66 years old). The patients were admitted to the clinic because of hyperlipoproteinaemia or atherosclerotic disease or both. No patient had secondary hyperlipoproteinaemia.

\section{Laboratory methods}

The serum triglyceride and the serum cholesterol concentrations were determined in propanol extracts by semi-automatic methods in a Technicon AutoAnalyzer type II (Rush et al. 1971) in whole serum and in the top fraction (corresponding to the very-low-density lipoproteins (VLDL)) and the bottom fraction at density 1.006 after preparative ultracentrifugation (Havel et al. 1955). LDL were precipitated from the bottom fraction, using a heparin-manganese chloride solution and the HDL-lipid concentrations were determined in the supernatant fraction (Burstein \& Samaille, 1960). A detailed description has been presented elsewhere (Vessby et al. 1980a).

The concentrations of apolipoprotein (apo) B, A-I and A-II were determined by electroimmunoassay as presented elsewhere (Vessby et al. 1980a). The apolipoprotein concentrations in serum are expressed as arbitrary units (A.U.) relative to the concentration in a reference serum, 100 A.U., obtained from a pool of healthy blood donors.

The fat content of the food was determined after extraction with chloroform-methanol and measured by weighing as described elsewhere (Boberg et al. 1981). The fatty acid compositions of the food and the blood plasma lipids were determined by gas-liquid chromatography (Boberg et al. 1981).

\section{Statistics}

Means and standard errors were calculated by ordinary methods. Confidence-interval tests of the hypothesis of equal means for the difference between the two treatments are, for each variable, based on the standard error for the difference and the $t$ distribution.

\section{RESULTS}

\section{Effects of 3-weeks dietary treatment on serum lipid concentrations}

After the first 3 weeks on lipid-lowering diets with P:S values of 1.3 or $2 \cdot 0$, the serum triglycerides had decreased by 21,33 and $23 \%$ in the type II a, II b and IV patients respectively. During the same period the serum cholesterol concentrations were reduced by 18,16 and $21 \%$ in patients with HLP types II a, II b and IV respectively. 
Table 3. Comparisons of serum lipid concentrations in patients with hyperlipoproteinaemia $(H L P)$ during treatmemt with lipid-lowering diets with polyunsaturated : saturated fat $(P: S)$ values of 1.3 and $2 \cdot 0$

(Mean values were calculated from the average value of serum lipid concentrations taken on three different days at the end of the diet periods for each patient; no. of patients in parentheses)

\begin{tabular}{|c|c|c|c|c|c|}
\hline & \multirow[b]{3}{*}{ HLP type } & \multicolumn{3}{|c|}{ Serum lipid concentrations $(\mathrm{mmol} / \mathrm{l})$} & \multirow{3}{*}{$\begin{array}{l}\text { Mean difference } \\
\text { between treatments and } \\
95 \% \text { confidence interval }\end{array}$} \\
\hline & & \multirow{2}{*}{$\begin{array}{c}\text { At } \\
\text { admission }\end{array}$} & \multicolumn{2}{|c|}{$P: S$ value of diet } & \\
\hline & & & $1 \cdot 3$ & $2 \cdot 0$ & \\
\hline Triglycerides & $\begin{array}{l}\text { II a } \\
\text { IIb } \\
\text { IV }\end{array}$ & $\begin{array}{l}1 \cdot 60 \\
4 \cdot 07 \\
5 \cdot 35\end{array}$ & $\begin{array}{l}1 \cdot 59 \\
2 \cdot 66 \\
3 \cdot 98\end{array}$ & $\begin{array}{l}1 \cdot 60 \\
2 \cdot 69 \\
4 \cdot 19\end{array}$ & $\begin{array}{l}-0.01 \pm 0.23(6) \\
-0.04 \pm 0.28(8) \\
-0.21 \pm 0.34(6)\end{array}$ \\
\hline Cholesterol & $\begin{array}{l}\text { II a } \\
\text { II b } \\
\text { IV }\end{array}$ & $\begin{array}{l}9 \cdot 07 \\
8 \cdot 67 \\
7 \cdot 92\end{array}$ & $\begin{array}{l}7 \cdot 27 \\
7 \cdot 15 \\
6 \cdot 20\end{array}$ & $\begin{array}{l}7 \cdot 24 \\
6 \cdot 74 \\
6 \cdot 08\end{array}$ & $\begin{array}{l}0.03 \pm 0.64(6) \\
0.41 \pm 0.56(8) \\
0.12 \pm 0.42(6)\end{array}$ \\
\hline
\end{tabular}

Comparisons of the effects of treatment with lipid-lowering diets with $P: S$ values of 1.3 and $2 \cdot 0$

Body-weight. The mean (with SEM) body-weight of the patients with HLP type II a at admission was $71 \cdot 0(2 \cdot 9) \mathrm{kg}$, of the type II b patients $71 \cdot 3(3.3) \mathrm{kg}$ and of the type IV patients $69 \cdot 2(4.4) \mathrm{kg}$. On average the body-weight did not change significantly in any of the three groups during the study.

Serum lipid concentrations (Table 3). The serum cholesterol and the serum triglyceride concentrations were not significantly different when compared after treatment with diets with $\mathrm{P}: \mathrm{S}$ values of $1 \cdot 3$ and $2 \cdot 0$.

Serum lipoprotein concentrations (Table 4). The concentrations of the serum lipoprotein lipids and apolipoproteins were very similar after treatment with the diet with a $P: S$ value of 1.3 and that with a P:S value of $2 \cdot 0$. The LDL-cholesterol concentration in the type II b patients only showed a further significant reduction of $9 \%(P<0.05)$ when the $\mathrm{P}: \mathrm{S}$ value was $2 \cdot 0$.

Fatty acid composition (Table 5). Similar changes in the fatty acid composition of the plasma lipid esters were seen in types II a, II b and IV. A significant increase in the polyunsaturated fatty acids (linoleic and arachidonic acids), and a decrease in the saturated fatty acids and oleic acid were observed in most of the lipid-ester fractions when the values at admission were compared with those obtained after 3 weeks on the lipid-lowering diets. Slight but significant differences in the fatty acid compositions were observed between the results after 3 weeks on the diet with a $P: S$ value of 1.3 and 3 weeks on the diet with a $P: S$ value of $2 \cdot 0$. Thus, increasing the $P: S$ value from $1 \cdot 3$ to $2 \cdot 0$ caused a slight further increase in linoleic acid content in the cholesterol esters and the triglycerides and a decrease of the myristic and oleic acids in all plasma lipid esters.

\section{DISCUSSION}

The reduction in serum cholesterol and serum triglycerides during treatment was similar to that reported earlier with lipid-lowering diets (Shepherd et al. 1978; Shepherd et al. 1980; Ernst et al. 1980; Vessby et al. $1980 a, b$; Lewis et al. 1981; Schaefer et al. 1981; Chait et al. 1974) indicating an adequate composition of the diets. Only in the type II b patients (Table 4) was a more pronounced reduction in the LDL concentration achieved on the diet with a $P: S$ value of 2.0 than on the diet with a $P: S$ value of 1.3 . Thus is seems that varying the 
Table 4. Comparison of serum lipoprotein concentrations (mmol/l) and serum apolipoprotein concentrations (arbitrary units) in patients with hyperlipoproteinaemia type II a (n 6$), I I b(\mathrm{n} 8)$ and IV $(\mathrm{n} 6)$ with lipid-lowering diets with polyunsaturated: saturated fat $(P: S)$ values of 1.3 and $2 \cdot 0$

(Mean values, mean difference between the two diets and $95 \%$ confidence interval for the differences are given)

\begin{tabular}{|c|c|c|c|}
\hline & \multicolumn{2}{|c|}{$P: S$ value of diet } & \multirow{2}{*}{$\begin{array}{c}\text { Mean difference } \\
\text { between treatments and } \\
95 \% \text { confidence interval }\end{array}$} \\
\hline & $1 \cdot 3$ & $2 \cdot 0$ & \\
\hline \multicolumn{4}{|l|}{ Type II a } \\
\hline VLDL TG & 0.71 & 0.73 & $-0.02 \pm 0.11$ \\
\hline VLDL Chol & 0.42 & 0.33 & $0.09 \pm 0.13$ \\
\hline LDL TG & 0.55 & 0.51 & $0.04 \pm 0.18$ \\
\hline LDL Chol & $5 \cdot 51$ & 5.49 & $0.02 \pm 0.26$ \\
\hline HDL TG & $0 \cdot 22$ & $0 \cdot 21$ & $0.01 \pm 0.03$ \\
\hline HDI Chol & $1 \cdot 22$ & $1 \cdot 22$ & $0.00 \pm 0.13$ \\
\hline Apo B & 175 & 173 & $2 \pm 42$ \\
\hline Apo A-I & 111 & 114 & $-3 \pm 7$ \\
\hline Apo A-II & 117 & 118 & $-1 \pm 8$ \\
\hline \multicolumn{4}{|l|}{ Type II b } \\
\hline VLDL TG & $1 \cdot 66$ & $1 \cdot 86$ & $-0.19 \pm 0.33$ \\
\hline VLDL Chol & 0.75 & 0.80 & $-0.05 \pm 0.12$ \\
\hline LDL TG & 0.64 & 0.58 & $0.06 \pm 0.08$ \\
\hline LDL Chol & $5 \cdot 35$ & $4 \cdot 86$ & $0.50 \pm 0.46^{*}$ \\
\hline HDL TG & 0.20 & 0.22 & $-0.02 \pm 0.06$ \\
\hline HDL Chol & 0.89 & 0.88 & $0.01 \pm 0.08$ \\
\hline Apo B & 182 & 175 & $7 \pm 12$ \\
\hline Apo A-I & 97 & 96 & $1 \pm 5$ \\
\hline Apo A-II & 107 & 106 & $1 \pm 4$ \\
\hline \multicolumn{4}{|l|}{ Type IV } \\
\hline VLDL TG & 3.03 & $2 \cdot 91$ & $0.11 \pm 0.45$ \\
\hline VLDL Chol & $1 \cdot 20$ & $1 \cdot 21$ & $-0.01 \pm 0.02$ \\
\hline LDL TG & 0.53 & 0.53 & $-0.00 \pm 0.16$ \\
\hline LDL Chol & $4 \cdot 14$ & $4 \cdot 14$ & $-0.00 \pm 0.45$ \\
\hline HDL TG & 0.25 & 0.24 & $0.01 \pm 0.12$ \\
\hline HDL Chol & 0.84 & 0.79 & $0.05 \pm 0.13$ \\
\hline Apo B & 162 & 153 & $9 \pm 29$ \\
\hline Apo A-I & 95 & 92 & $3 \pm 8$ \\
\hline Apo A-II & 96 & 93 & $3 \pm 4$ \\
\hline
\end{tabular}

VLDL, very-low-density-lipoprotein; LDL, low-density-lipoprotein; HDL, high-density-lipoprotein; TG, triglycerides; Chol, cholesterol; Apo, apolipoproteins.

* Significant change, $0.01<P<0.05$.

dietary $P: S$ value had no major effect on the extent of serum lipoprotein reduction during treatment. In particular, our hypothesis that the HDL reductions might be less pronounced with a diet with a lower $\mathrm{P}: \mathrm{S}$ value was not confirmed.

Interestingly enough, it was shown that the linoleic acid contents of the cholesterol esters and phospholipids were very similar at the end of the two different dietary periods (Table 5). A somewhat greater difference was seen with regard to the composition of the triglycerides. While the fatty acid composition of the triglycerides merely reflects the dietary composition during the last days before testing, the fatty acid composition of the cholesterol esters and phospholipids changes more gradually during a 2-3 week period and thus reflects the average dietary composition during a longer time-period (Boberg et al. 1978). Compared with those at admission, the linoleic acid contents of cholesterol esters and phospholipids 
Table 5. Fatty acid composition (mmol/mol) of serum triglycerides $(T G)$, cholesterol esters $(C E)$ and phospholipids $(P L)$ of twenty patients, on admission to hospital and on lipid-lowering diets with polyunsaturated: saturated fat $(P: S)$ values of 1.3 and 2.0

\begin{tabular}{|c|c|c|c|c|c|}
\hline \multirow[b]{3}{*}{ Fatty acid } & & \multicolumn{3}{|c|}{ Fatty acid composition } & \multirow{3}{*}{$\begin{array}{l}\text { Mean difference } \\
\text { between treatments and } \\
95 \% \text { confidence interval }\end{array}$} \\
\hline & & \multirow{2}{*}{$\underset{\text { admission }}{\text { At }}$} & \multicolumn{2}{|c|}{$P: S$ value of diet } & \\
\hline & & & $1 \cdot 3$ & $2 \cdot 0$ & \\
\hline $14: 0$ & $\begin{array}{l}\text { TG } \\
\text { CE } \\
\text { PL }\end{array}$ & $\begin{array}{l}2 \cdot 54 \\
1.08 \\
0.44\end{array}$ & $\begin{array}{l}1.96 \\
0.74 \\
0.37\end{array}$ & $\begin{array}{l}1 \cdot 66 \\
0 \cdot 60 \\
0 \cdot 30\end{array}$ & $\begin{array}{l}0.30 \pm 0.17^{* *} \\
0.15 \pm 0.08^{* *} \\
0.06 \pm 0.03^{* * *}\end{array}$ \\
\hline $16: 0$ & $\begin{array}{l}\text { TG } \\
\text { CE } \\
\text { PL }\end{array}$ & $\begin{array}{l}27 \cdot 03 \\
12 \cdot 37 \\
33 \cdot 94\end{array}$ & $\begin{array}{l}22.63 \\
10 \cdot 89 \\
31 \cdot 74\end{array}$ & $\begin{array}{l}21 \cdot 76 \\
10 \cdot 52 \\
31 \cdot 68\end{array}$ & $\begin{array}{l}0.87 \pm 0.71^{*} \\
0.37 \pm 0.29^{*} \\
0.06 \pm 0.51\end{array}$ \\
\hline $16: 1 \omega 7$ & $\begin{array}{l}\text { TG } \\
\text { CE } \\
\text { PL }\end{array}$ & $\begin{array}{l}6 \cdot 22 \\
4 \cdot 61 \\
1 \cdot 53\end{array}$ & $\begin{array}{l}5 \cdot 39 \\
2.56 \\
1.36\end{array}$ & $\begin{array}{l}5 \cdot 21 \\
2 \cdot 22 \\
1 \cdot 30\end{array}$ & $\begin{array}{l}0 \cdot 19 \pm 0.29 \\
0.34 \pm 0 \cdot 27^{*} \\
0.06 \pm 0 \cdot 10\end{array}$ \\
\hline $18: 0$ & $\begin{array}{l}\text { TG } \\
\text { CE } \\
\text { PL }\end{array}$ & $\begin{array}{r}4 \cdot 36 \\
1 \cdot 18 \\
16 \cdot 64\end{array}$ & $\begin{array}{r}3 \cdot 60 \\
0 \cdot 99 \\
16 \cdot 68\end{array}$ & $\begin{array}{r}3.45 \\
1.05 \\
17.09\end{array}$ & $\begin{array}{l}0.15 \pm 0.12^{*} \\
-0.05 \pm 0.11 \\
-0.41 \pm 0.46\end{array}$ \\
\hline $18: 1 \omega 9$ & $\begin{array}{l}\text { TG } \\
\text { CE } \\
\text { PL }\end{array}$ & $\begin{array}{l}39 \cdot 29 \\
19 \cdot 59 \\
13 \cdot 18\end{array}$ & $\begin{array}{l}33.99 \\
13.48 \\
10.76\end{array}$ & $\begin{array}{l}32 \cdot 52 \\
12 \cdot 97 \\
10 \cdot 41\end{array}$ & $\begin{array}{l}1.47 \pm 0.93^{*} \\
0.51 \pm 0.45^{*} \\
0.36 \pm 0.31^{*}\end{array}$ \\
\hline $18: 2 \omega 6$ & $\begin{array}{l}\text { TG } \\
\text { CE } \\
\text { PL }\end{array}$ & $\begin{array}{l}18 \cdot 35 \\
55 \cdot 56 \\
24 \cdot 95\end{array}$ & $\begin{array}{l}30 \cdot 04 \\
65 \cdot 63 \\
29 \cdot 14\end{array}$ & $\begin{array}{l}33 \cdot 33 \\
66 \cdot 93 \\
29 \cdot 72\end{array}$ & $\begin{array}{l}-3.29 \pm 1.53^{* * *} \\
-1.30 \pm 0.64^{* * *} \\
-0.57 \pm 0.46^{*}\end{array}$ \\
\hline $18: 3 \omega 3$ & $\begin{array}{l}\text { TG } \\
\text { CE } \\
\text { PL }\end{array}$ & $\begin{array}{l}1.29 \\
0.64 \\
0.34\end{array}$ & $\begin{array}{l}1 \cdot 32 \\
0 \cdot 35 \\
0 \cdot 14\end{array}$ & $\begin{array}{l}0.99 \\
0.30 \\
0.11\end{array}$ & $\begin{array}{l}0.32 \pm 0 \cdot 17^{* * * *} \\
0.05 \pm 0 \cdot 14 \\
0.03 \pm 0.06\end{array}$ \\
\hline $20: 4 \omega 6$ & $\begin{array}{l}\text { TG } \\
\text { CE } \\
\text { PL }\end{array}$ & $\begin{array}{l}0.92 \\
4.98 \\
9 \cdot 07\end{array}$ & $\begin{array}{l}1.07 \\
5 \cdot 35 \\
9 \cdot 82\end{array}$ & $\begin{array}{l}1.09 \\
5.42 \\
9 \cdot 40\end{array}$ & $\begin{array}{r}-0.01 \pm 0.08 \\
-0.07 \pm 0.27 \\
0.42 \pm 0.58\end{array}$ \\
\hline
\end{tabular}

Mean values were significantly different from those for a P:S value of $1 \cdot 3:{ }^{*} P<0 \cdot 05,{ }^{* *} P<0 \cdot 01,{ }^{* * *} P<0 \cdot 001$

were highly significantly increased after giving the diet with a $P: S$ value of 1.3 for 3 weeks (Table 5). There was a significant, but very slight, increase in the cholesterol ester content of linoleic acid when comparing the fatty acid compositions at the end of treatment with the diet with a $P: S$ value of 2.0 with that on the diet with a $P: S$ value of $1 \cdot 3$. There was no significant increase of the content of $18 \cdot 2 \omega 6$ in the phospholipids.

It has been suggested that the fatty acid composition of the LDL, as reflected by the fatty acid composition in the cholesterol esters in plasma, might affect the elimination rate of the lipoproteins from plasma (Deckelbaum et al. 1977). The reduction in LDL-cholesterol during treatment with polyunsaturated fat has been suggested to be due to decreased synthesis (Deckelbaum et al. 1977; Gordon et al. 1977; Boberg et al. 1981). An increased catabolic rate of LDL may be due to an altered membrane fluidity of LDL (Morrisett $e t$ al. 1977) or changed properties of the receptors (Jackson $e t$ al. 1978). If we assume that the fatty acid composition of the lipoproteins is related to the metabolic fate of these particles the very modest increase in the polyunsaturated fat content of plasma lipid esters when increasing the $\mathrm{P}: \mathrm{S}$ value from 1.3 to 2.0 may explain the lack of major differences in the LDL concentration. There seems to be a saturation point, at least during relatively 
short-term studies, with regard to the possible incorporation of polyunsaturated fatty acids into plasma lipoproteins.

In conclusion, the present study indicates that increasing the $\mathrm{P}: \mathrm{S}$ ratio of lipid-lowering diets from 1.3 to 2.0 does not offer any great advantages with regard to lipoprotein-lipid reduction in patients with moderate hyperlipoproteinaemia. The situation may be different in familial hypercholesterolaemia with massively-increased LDL-cholesterol concentrations. The effects on LDL- and HDL-cholesterol were not dissociated by decreasing the amount of polyunsaturated fats in the present study. It is possible that advice given to patients with moderate hyperlipoproteinaemia may be modified with regard to the amount of polyunsaturated fat, thus giving the patients a greater freedom in the choice of foodstuffs which would make it easier to adhere to the prescribed diet.

\section{REFERENCES}

Beaumont, J. L., Carlson, L. A., Cooper, G. R., Fejfar, Z., Fredrickson, D. S. \& Strasser, T. (1970). Bulletin of the World Health Organization 42, 891-915.

Boberg, J., Gustafsson, I.-B., Karlström, B., Lithell, H., Vessby, B. \& Werner, I. (1978). Rheinisch-Westfälische Akademie der Wissenschaften 63, 81-87.

Boberg, J., Gustafsson, I.-B., Karlström, B., Lithell, H., Vessby, B. \& Werner, I. (1981). Annals of Nutrition and Metabolism 25, 320-331.

Burstein, M. \& Samaille, J. (1960). Clinica Chimica Acta 5, 609.

Chait, A., Onitiri, A., Nicoll, A., Rabaya, E., Davies, J. \& Lewis, B. (1974). Atherosclerosis 20, 347-364.

Deckelbaum, R. J., Shipley, G. G., Tall, A. R. \& Small, D. M. (1977). In Protides of the Biological Fluids, vol. 25, pp. 91-98 [H. Peeters, editor]. New York: Pergamon Press.

Ernst, N., Fisher, M., Bowen, P., Schaefer, E. J. \& Levy, R. I. (1980). Lancet ii, 111-113.

Gordon, T., Castelli, W. P., Hjortland, M. C., Kannel, W. B. \& Dawber, T. R. (1977). American Journal of Medicine 62, 707-714.

Havel, R. J., Eder, H. H. \& Bragdon, J. H. (1955). Journal of Clinical Investigation 34, 1345-1353.

Jackson, R. L., Taunton, O. D., Morrisett, J. D. \& Gotto, A. M. Jr (1978). Circulation Research 42, $447-453$.

Langer, T., Levy, R. I. \& Fredrickson, D. S. (1969). Circulation 40 (Suppl. III), 14 (Abstr.).

Lewis, B., Katan, M., Merkx, I., Miller, N. E., Hammet, F., Kay, R. M., Nobels, A. \& Swan, A. V. (1981). Lancet ii, $1310-1313$.

Morrisett,J. D.,Pownall,H. J.,Jackson, R. L.,Segura, R., Gotto, A. M.\&Taunton,O. D.(1977). In Polyunsaturated Fatty Acids, pp. 139-161 [R. T. Holman, W. H. Kunau and I. U. Champaign, editors]. Washington DC: American Oil Chemists' Society.

Rush, R. J., Leon, L. \& Turrell, J. (1971). Advances in Automatic Analyses 1, 503-507.

Schaefer, E. J., Levy, R. I., Ernst, N. D., van Saut, F. D. \& Brewer, H. B. (1981). American Journal of Clinical Nutrition 34, 1758-1763.

Shepherd, J., Packard, C. J., Grundy, S. M., Yeshurun, D., Gotto, A. M. Jr \& Taunton, O. D. (1980). Journal of Lipid Research 21, 91-99.

Shepherd, J., Packard, C. J., Patsch, J. R., Gotto, A. M. Jr \& Taunton, O. D. (1978). Journal of Clinical Investigation 61, 1582-1592.

Vessby, B., Boberg, J., Gustafsson, I.-B., Karlström, B., Lithell, H. \& Östlund-Lindqvist, A.-M. (1980a). Atherosclerosis 35, 21-27.

Vessby, B., Gustafsson, I.-B., Boberg, J., Karlström, B., Lithell, H. \& Werner, I. (1980b). European Journal of Clinical Investigation 10, 193-202. 